\title{
PENTINGNYA PENGETAHUAN PERAWAT TERHADAP SASARAN KESELAMATAN PASIEN DI RUMAH SAKIT
}

\author{
Esty Purnama Sari
}

Estypurnamasari97@gmail.com

\section{Latar Belakang}

Sasaran Keselamatan Pasien merupakan suatu bagian dari Standar Akreditasi Rumah Sakit yang harus dapat diterapkan di rumah sakit yang berguna dalam meningkatkan pelayanan kesehatan yang berkualitas. Maksud dari Sasaran Keselamatan Pasien adalah mendorong peningkatan spesifik dalam keselamatan pasien. Sasaran ini menyoroti area yang bermasalah dalam pelayanan kesehatan dan menguraikan tentang solusi atas konsensus berbasis bukti dan keahlian terhadap permasalahan ini. Patient Safety adalah suatu sistem yang mencegah terjadinya Kejadian Tidak Diharapkan (KTD) akibat tindakan yang dilakukan atau bahkan tidak dilakukan oleh tenaga medis maupun non medis. Sistem tersebut meliputi: assessmen resiko, identifikasi dan pengelolaan hal yang berhubungan dengan risiko pasien, pelaporan dan analisis insiden, kemampuan belajar dari insiden dan tindak lanjutnya serta implementasi solusi untuk meminimalkan timbulnya resiko (Depkes, 2008). Untuk dapat membudidayakan keselamatan pasien maka langkah awal yang diperlukan bagi perawat adalah pengetahuan. Secara konsep pengetahuan merupakan domain yang penting untuk terbentuknya perilaku terbuka (Sunaryo, 2004). Pengetahuan perawat dalam Sasaran Keselamatan Pasien terdiri dari ketepatan identifikasi pasien, peningkatan komunikasi yang efektif, peningkatan keamanan obat yang perlu diwaspadai kepastian tepat lokasi, tepat prosedur, dan tepat pasien operasi, pengurangan risiko infeksi terkait pelayanan kesehatan, pengurangan risiko pasien jatuh. Pada saat ini setiap rumah sakit diwajibkan untuk meningkatkan mutu pelayanan kesehatan yang salah satunya adalah melalui 
sasarankeselamatan pasien. Rumah sakit merupakan salah satu tempat yang memberikan pelayanan kesehatan pada pasien, dengan berbagai macam jenis tenaga kesehatan diantaranya adalah perawat dan dokter. Tenaga kesehatan yang bekerja di rumah sakitbertanggung jawab dalam meningkatkan mutu pelayanan kesehatan dalam pengelolaan manajemen resiko keselamatan pasien di rumah sakit (Kemenkes dan KARS, 2011). Tujuan dalam penelitian ini adalah untuk mengidentifikasi pengetahuan perawat dalam Sasaran Keselamatan Pasien di rumah sakit. Hasil penelitian adalah dilihat berdasarkan masing- masing sasaran didapatkan bahwa semua sasaran keselamatan pasien hampir seluruhnya berada pada kategori kurang baik.

Kata Kunci : Pengetahuan Perawat, Sasaran Keselamatan Pasien, Rumah Sakit

\section{Metode}

Metode yang digunakan dalam Penulisan Jurnal ini diawali dengan pemilihan topik, kemudian menulisakan kata kunci "Pengetahuan perawat", "Sasaran keselamatan pasien", dan "Rumah sakit". Desain penelitian dari setiap jurnal yaitu deskriptif analitik dengan pendekatan cross sectional. Intrument penelitian untuk variabel independen menggunakan kuisioner dan variabel dependen menggunakan checklist. Dan hasil disajikan secara deskriptif dengan metode studi kasus (case study) yang mengambil sampel dari populasi dan menggunakan panduan wawancara dan panduan observasi dan telusur dokumen sebagai instrumen pengumpul data. Populasi penelitian ini adalah seluruh perawat pelaksana di rumah sakit. Dari hasil pencarian kemudian diolah dan dianalisis sehingga menghasilkan sebuah pembahasan dan kesimpulan dari topik yang ditetapkan. Sumber penelitian ini berasal dari beberapa literature jurnal, Jurnal ini dibatasi dengan tahun paling tua 2012. Jumlah referensi jurnal yang digunakan sebanyak 12 referensi jurnal.

\section{Hasil}


Hasil penelitian Arruum, D., Dkk (2015) didapatkan bahwa 63,8\% pengetahuan tenaga kesehatan dalam keselamatan pasien pada kategori kurang baik. Hasil penelitian tersebut sejalan dengan hasil penelitian yang dilakukan oleh Surahmat, R, dkk (2018) dimana sasaran keselamatan pasien oleh perawat menunjukkan bahwa dari 96 perawat, 81 perawat $(84,4 \%)$ dengan kategori implementasi sasaran keselamatan pasien baik dan 15 perawat $(15,6 \%)$ dengan kategori implementasi sasaran keselamatan pasien kurang baik. Namun, tidak sejalan dengan hasil penelitian yang dilakukan oleh Cahyono, A (2015) dimana pengelompokkan tingkat pengetahuan baik dan kurang didapatkan hasil diketahui bahwa dari 43 responden perawat yang memiliki pengetahuan kurang berjumlah 13 orang $(30,2 \%)$ dan perawat yang memiliki pengetahuan baik berjumlah 30 orang $(69,7 \%)$. Sebagian besar responden ( $>50 \%$ perawat) memiliki pengetahuan yang baik tentang keselamatan pasien. Hal ini berarti tenaga kesehatan seperti perawat masih mengambarkan belum mengetahui pentingnya menjaga keselamatan pasien pada saat memberikan tindakan baik medis atau keperawatan. Tenaga perawat yang bekerja di rumah sakit masih banyak yang belum mengetahui tentang keselamatanpasien, pada hal keselamatan pasien merupakan suatu standar dari Kementerian Kesehatan dan PERSI sejak tahun 2011. Ini menunjukkan peran serta pemimpin rumah sakit dalam meningkatkanmutu pelayanan masih perlu di monitoring secara optimal agar pimpinan dapat terus mengaplikasikan tuntutan standar yang harus dilaksanakan. Apabila dilihat berdasarkan masing- masing sasaran didapatkan bahwa semua sasaran keselamatan pasien hampir seluruhnya berada pada kategori kurang baik. Pengetahuan tenaga kesehatan dalam Sasaran Keselamatan Pasien terdiri dari Sasaran I adalah Ketepatan Identifikasi Pasien, Sasaran II adalah Peningkatan komunikasi yang efektif, Sasaran III adalah Peningkatan keamanan obat yang perlu diwaspadai, Sasaran IV adalah Kepastian tepat lokasi,tepat prosedur, dan tepat pasien operasi, Sasaran IV adalah Pengurangan risiko infeksi terkait pelayanan kesehatan, Sasaran VI adalah Pengurangan risiko pasien jatuh (Direktoran BUN, Kemenkes, dan KARS,2011).

\section{Pembahasan}




\section{A. Identifikasi Pasien}

Hasil penelitian menyebutkan bahwa hambatan dalam mengidentifkasi pasien adalah pasien merasa terbebani dan bosan saat diminta menyebutkan identitasnya. Kondisi tersebut serupa dengan temuan Joint Committee International di beberapa negara bahwa salah satu hambatan dalam identifikasi pasien adalah ketidaknyamanan pasien karena pengulangan pertanyaan (Greenly, 2006). Cara mengatasi hambatan identifikasi adalah dengan mensosialisasikan tentang prosedur dan tujuan identifikasi pasien sejak pasien masuk ruang rawat inap. Cara tersebut telah sesuai dengan saran yang diberikan oleh $\mathrm{JCl}$ yaitu mengedukasi pasien dan keluarga tentang risiko yang berhubungan dengan kesalahan identifikasi ( $\mathrm{JCl}, 2007)$. Cara untuk mengatasi hambatan identifikasi pasien adalah dengan melakukan variasi pertanyaan, seperti mengganti tanggal lahir dengan ulang tahun. Variasi sebagai keanekaan yang membuat sesuatu tidak menoton. Variasi dapat berwujud perubahan atau perbedaan yang sengaja diciptakan untuk memberikan kesan yang unik. Variasi dilakukan untuk mengurangi kejenuhan dan meningkatkan perhatian terhadap suatu objek (John,2008).

\section{B. Peningkatan Komunikasi Efektif}

Untuk meningkatkan komunikasi efektif, digunakan teknik SBAR, catatan perkembangan pasien juga ditulis menggunakan format SBAR, yang terdiri atas situation atau kondisi pasien, background atau latar belakang kondisi pasien, assessment atau hasil pengkajian dan pemeriksaan, dan recommendation atau tindakan yang diberikan. Menurut Catherine (2011) SBAR telah menjadi standar untuk berkomunikasi dalam situasi perawatan pasien. SBAR efektif dalam menjembatani perbedaan dalam gaya komunikasi dan membantu untuk mendapatkan persamaan persepsi antar tim medis. Hambatan dalam berkomunikasi dengan SBAR adalah memerlukan waktu yang cukup banyak sehingga terdapat dokter yang enggan dilakukan konfirmasi read back. Hasil penelitian ini identik dengan penelitian oleh Altair J (2009). Menurut penelitian Cassandra (2012) maka hambatan ini termasuk dalam human factor, yaitu kurangnya pengetahuan. Cara mengatasi hambatan berupa kurangnya pengetahuan dalam 
menggunakan teknik SBAR, dengan mengadakan belajar bersama dan mentoring tentang teknik SBAR. Hasil review atas pelaksanaan mentoring menyatakan bahwa mentoring dapat mengatasi kekurangan tenaga perawat, meningkatkan kepuasan perawat serta memperbaiki kualitas pelayanan (Block \& Korow, 2005).

\section{Peningkatkan keamanan terhadap}

Obat yang perlu diwaspadaipanduan sasaran keselamatan pasien dari JCI (2008) yang menyatakan bahwa Obat- obatan yang sering disebutkan dalam isu keselamatan pasien adalah pemberian elektrolit konsentrat secara tidak sengaja (misalnya, kalium klorida $2 \mathrm{meq} / \mathrm{ml}$ atau yang lebih pekat, kalium fosfat, natrium klorida lebih pekat dari $0.9 \%$, dan magnesium sulfat $=50 \%$ atau lebih pekat). Obat - obat high alert akan diberikan stiker khusus warna merah bertuliskan high alert, kemudian disimpan di dalam troli emergency, dan tidak disediakan di ruangan secara sembaranganelektrolit konsentrat tidak berada di unit pelayanan pasien kecuali jika dibutuhkan secara klinis. Elektrolit konsentrat yang disimpan pada unit pelayanan pasien harus diberi label yang jelas, dan disimpan pada area yang dibatasi ketat $(\mathrm{JCl}, 2008)$. Hasil penelitian tersebut identik dengan penelitian oleh Altair (2009) yang menyebutkan bahwa hambatan perawat dalam mewaspadai penggunaan obat high alert antara lain adalah pengetahuan tentang obat high alert tidak adekuat dan beban kerja yang cukup menekan bagi perawat. Berdasarkan hasil penelitian ini partisipan menyatakan bahwa perawat akan melakukan pembimbingan atau mentoring tentang jenis - jenis obat high alert dan cara penggunaannya. Perawat yang masih baru tentu masih sedikit pengalaman dan pengetahuannya tentang obat high alert sehingga membutuhkan bimbingan dari perawat yang senior. Mentoring memberikan berbagai keuntungan seperti menjembatani jurang antara teori dan praktek, meningkatkan pemikiran kritis dan pengembangan karir, dan mengingkatkan profesionalisme perawat baru (Block \&Korrow, 2005). 
D. Memastikan tindakan bedah yang benar letak, prosedur, dan pasien

Penandaan lokasi operasi bukan merupakan kewenangan perawat, melainkan kewenangan dokter operator. Hambatan dalam memastikan benar letak adalah terdapat dokter yang tidak bersedia menandai lokasi operasi. Selain itu dua partisipan menyatakan bahwa pada kondisi tertentu operasi dilakukan dan dokter belum sempat visite, sehingga penandaan belum sempat dilakukan. Hambatan tersebut identik dengan hasil penelitian John R Clark (2012) yang menyatakan bahwa salah satu hambatan dalam melakukan penandaan lokasi operasi adalah physician's behavior.

\section{E. Pencegahan risiko infeksi terkait}

pelayanan kesehatan cara untuk mengurangi risiko infeksi adalah melalui cuci tangan. Lima waktu cuci tangan atau disebut dengan five moment, yaitu sebelum ke pasien, setelah dari pasien, setelah melakukan tindakan aseptic, setelah terkena cairan pasien, dan setelah dari lingkungan pasien. Selain itu, dua partisipan mengatakan hambatan untuk cuci tangan adalah lupa. Hasil tersebut sama seperti penelitian yang dilakukan oleh Janet E Squires, dkk (2013) yang menyatakan bahwa salah satu hambatan dalam melakukan cuci tangan adalah hambatan individu atau personal seperti perilaku/kebiasaan, termasuk lupa. Solusi yang dilakukan partisipan untuk meningkatkan kepatuhan dalam cuci tangan adalah dengan berusaha membiasakan dan merubah mindset bahwa cuci tangan bukan semata - mata untuk mesukseskan program rumah sakit, tapi juga untuk kebaikan diri sendiri agar tidak tertular penyakit dari rumah sakit. Solusi tersebut sesuai dengan penelitian oleh Janet E Clark (2013) bahwa cara untuk meningkatkan kepatuhan dalam cuci tangan adalah melalui behavior therapy atau terapi untuk membentuk kebiasaan yang merupakan sebuah proses 
berkesinambungan dimana salah satu prosesnya adalah dengan membentuk pola pikir atau mindset.

\section{F. Pencegahan risiko jatuh}

Cara untuk mencegah risiko jatuh adalah dengan melakukan pengkajian risiko jatuh. pasien diketahui berisiko jatuh, maka pasien akan diberikan penanda yaitu kancing kuning bertuliskan fall risk yang disematkan di gelang pasien. Selanjutnya partisipan akan melakukan intervensi terkait risiko jatuh seperti memasang pengaman samping bed dan memperhatikan lingkungan sekitar yang menyebabkan pasien jatuh, mendampingi pasien saat mobilisasi, serta mengedukasi keluarga tentang risiko jatuh yang dialami pasien. Prosedur tersebut seperti dalam panduan fall prevention strategy yang menyebutkan cara untuk mencegah risiko jatuh adalah dengan memberikan penanda pada pasien, melakukan standar intervensi pada risiko jatuh, serta mengedukasi pasien dan keluarga. (Krista, 2011).

Apabila dilihat berdasarkan masing- masing sasaran didapatkan bahwa semua sasaran keselamatan pasien hampir seluruhnya berada pada kategori kurang baik. Apabila dilihat berdasarkan identifikasi pasiendidapatkan tenaga kesehatan masih tidak mengetahui standar pertama dari IPSG (International Pasient Safety Goals) dan yang kedua yaitu Situation BackgroundAssessment Recomendation (SBAR).

Apabila dilihat berdasarkan komunikasi efektif masih terdapat kekurangan perawat baik saat pelaporan dengan menggunakan Situation, Background, Assessment, danRekommendation (SBAR) maupun saat komunikasi melalui telepon.

Apabila dilihat dari keamanan terhadap obat didapatkan bahwa masih ditemukan tenaga keseahatan yang belummengeahui warna gelang pasien yang berisiko alergi. 
Apabila dilihat dari Memastikan tindakan bedah yang benar letak, prosedur, dan tepat operasi pasien didapatkan bahwa masih ada tenaga kesehatan yang belum mengetahui secara konsep urutan IPSG keempat, dan masih ada yang belum memahami tentang sitemarking.

Apabila dilihat dari pengendalian infeksi didapatkan bahwa masih ada ditemukan tenaga kesehatan yang belum mengingat cuci tangan 6 langkah dan belummemahami cuci tangan five moment. Hasil penelitian yang dilakukan Nurjannah dan Arruum (2015) didapatkan bahwa paling banyak perawat pada kategori kurang baik dalam melakukan cuci tangan five moment.

Apabila dilihat dari pencegahan pasien jatuh didapatkan bahwa tenaga kesehatan belum memahami tentang penilaian risiko pasien jatuh pada pasien dewasa, anak., dan belum memahami warna gelang yang digunakan pada pasien jatuh, tidakmengetahui nama alat ukur yang digunakan untuk pasien jatuh. Pengetahuan perawat dan dokterterkait dengan pengendalian pasien jatuh perlu ditingkatkan dimana menurut Spoelstra, Given dan Given (2012) menyatakan bahwa banyak faktor untukpencegahan pasien jatuh seperti pengkajian pasien jatuh, pasang tanda risiko pasien jatuh pada tempat tidur dan pintu, modifikasi lingkungan, manajemen pemberian obat, membantu pasien ke toilet untuk mengurangi pasien jatuh.

\section{Penutup}

Dari berbagai uraian yang telah dijelaskan sebelumnya maka dapat disimpulkan bahwa dalam penelitian ini adalah tenaga kesehatan baik dokter dan perawat memiliki pengetahuan yang kurang baik tentang sasaran keamanan pasien di rumahsakit, yang menunjukkan bahwa identifikasi pasien, komunikasi efektif, keamanan obat, kepastian tepat lokasi, prosedur, pasien operasi, pengendalian infeksi, pencegahan pasien jatuh belum dipahami oleh tenaga kesehatan yaitu perawat dan dokter. Hal ini dapat diatasi dengan pengetahuan yang perlu diberikan secara berulang-ulang. Menurut Sunaryo 
(2004) dinyatakan bahwa pengetahuan merupakan domain yang penting untuk terbentuknya perilaku terbuka. Disarankan bagi rumah sakit dapat mengadakan seminar dan pelatihan secara berkala tentang Sasaran Keselamatan Pasien untuk meningkatkan kualitas pelayanan kesehatan.

\section{Daftar Pustaka}

1). Arruum, D., Salbiah., Manik, M. (2015). Pengetahuan Tenaga Kesehatan Dalam Sasaran Keselamatan Pasien Di Rumah Sakit Sumatera Utara (Knowledge of Health Workers in The Patient Safety in The Hospital of Sumatera Utara). Idea Nursing Journal, VI (2).

2). Cahyono, A. (2015). Hubungan Karakteristik Dan Tingkat Pengetahuan Perawat 
Terhadap Pengelolaan Keselamatan Pasien Di Rumah Sakit. Jurnal IImiah WIDYA, 3(2).

3). Isnaini, N, M., Rofii, M. (2014). Pengalaman Perawat Pelaksana Dalam Menerapkan Keselamatan Pasien. Jurnal Managemen Keperawatan, 2(1).

4). Neri, A, R., Yuniar, L., Husna Y. (2018). Analisis Pelaksanaan Sasaran Keselamatan Pasien Di Rawat Inap Rumah Sakit Umum DaerahPadang Pariaman. Jurnal Kesehatan Andalas, 7(Supplement 4).

5). Pambudi, Y, D, W., Sutriningsih, A., Yasin, D, D, F. (2018). Faktor-Faktor Yang Mempengaruhi Perawat Dalam Penerapan 6 SKP (Sasaran Keselamatan Pasien) Pada Akreditasi JCl (Joint Commission International) di Ruang Rawat Inap Rumah Sakit Panti Waluya Malang. Nursing News, 3(1).

6). Sakinah, S., Wigati, P, A., Arso, S, P. (2017). Analisis Sasaran Keselamatan Pasien Dilihat Dari Aspek Pelaksanaan Identifikasi Pasien Dan Keamanan Obat Di RS Kepresidenan RSPAD Gatot Soebroto Jakarta. JURNAL KESEHATAN MASYARAKAT (eJournal), 5(4).

7). Setiyani M, D., Zuhrotunida., Syahridal. (2016). Implementasi Sasaran Keselamatan Pasien Di Ruang Rawat Inap RSU Kabupaten Tanggerang. JKFT, Edisi Nomor 2.

8). Simamora, R. H. (2018). Buku ajar keselamatan pasien melalui timbang terima pasien berbasis komunikasi efektif: SBAR. Medan: USUpress.

9). Simamora, R. H. (2020). Learning of Patient Identification in Patient Safety Programs Through Clinical Preceptor Models. Medico Legal Update, 20(3), 553-556.

10). Sundoro, T., Rosa, E. M., \& Risdiana, I. (2016). Evaluasi Pelaksanaan Sasaran Keselamatan Pasien Sesuai Akreditasi Rumah Sakit Versi 2012 di Rumah Sakit Khusus Ibu dan Anak PKU Muhammadiyah Kotagede Yogyakarta. Jurnal Medicoeticolegal Dan Manajemen Rumah Sakit, 5(1), 40-48.

11). Yusuf, M. (2017). Penerapan Patient Safety Di Ruang Rawat Inap Rumah Sakit Umum Daerah Dr. Zainoel Abidin Patient Safety Implementation In Ward Of Dr Zainoel 
Abidin General Hospital. Jurnal IImu Keperawatan, 5(1).

12). Zakaria, F, M. (2017). Pengaruh Kualitas Pelayanan Dan Sasaran Keselamatan

Pasien Terhadap Kepuasan Pasien Rumah Sakit Prima Husada Malang. Jurnal I/mu Manajemen (JIMMU), 2(2). 